\title{
GÊNERO NO CAMPO: SIGNIFICADO DO GRUPO MOBI E AS EXPERIÊNCIAS DAS MULHERES INSERIDAS NA CAFEICULTURA EM POÇO FUNDO-MG
}

\author{
Camila Turmina BATICINI ${ }^{1}$
}

Flamarion Dutra ALVES

\section{Resumo}

\begin{abstract}
A abordagem sobre "gênero no campo" perpassa pelas relações de dominação e poder existentes no mundo rural, cujo ambiente tem sido palco de um crescente engajamento político das mulheres nas últimas décadas. Este estudo tem como objetivo a análise de um caso específico de organização de mulheres que fazem parte de um movimento de contestação dessa ordem, na medida em que os papéis deixam de ser atribuídos por conveniência ou por dominação: Mulheres Organizadas Buscando Independência, que trabalham sobretudo na cafeicultura orgânica no município de Poço Fundo-MG. A partir disto, norteia-se pela abordagem fenomenológica para o resgate da percepção das integrantes do grupo sob diversos temas, como: a relação da mulher com o campo; a importância da produção orgânica bem como as suas implicações; e a luta da mulher que busca independência. Busca-se, assim, compreender o significado do grupo em suas vidas para além da atividade econômica desempenhada.
\end{abstract}

Palavras-chave: Pertencimento. Agroecologia. Resistência.

\section{Abstract \\ Gender in the countryside: meaning of the MOBI group and the experiences of women inserted in coffee plantations in Poço Fundo-MG}

The approach on "gender in the field" permeates the relations of domination and power existing in the rural world, whose environment has been the scene of a growing political engagement of women in the last decades. The purpose of this study is to analyze a specific case of the organization of women who are part of a protest movement of this order, insofar as the roles are no longer attributed for convenience or domination: Organized Women Seeking Independence, who work mainly in organic coffee-growing in the municipality of Poço Fundo-MG. From this, it is guided by the phenomenological approach for the recovery of the perception of the members of the group under various themes, such as: the relation of the woman to the field; the importance of organic production as well as its implications; and the struggle of women seeking independence. It seeks, therefore, to understand the meaning of the group in their lives beyond the economic activity performed.

Key words: Belonging. Agroecology. Resistance.

\footnotetext{
1 Universidade Federal de Alfenas - MG, Graduanda em Geografia, membro do Grupo de Estudos Regionais e Socioespaciais-GERES. Endereço: Rua Plínio Leite da Silva, 1149. Jardim Alvorada. Alfenas -MG. CEP: 37135-250. E-mail: camilaturminabaticini@hotmail.com

2 Universidade Federal de Alfenas - MG, Professor Adjunto IV e líder do Grupo de Estudos Regionais e Socioespaciais-GERES. Endereço: Av. Jovino Fernandes Sales, 2600. UNIFAL-MG, Bairro Santa Clara, Alfenas-MG. CEP: 37133-840. E-mail: dutrasm@yahoo.com.br
} 


\section{INTRODUÇÃO}

Na compreensão do mundo rural, é notória a participação do homem em todos os aspectos que envolvem o campo, desde a produção - a partir da atividade do plantio, passando pela colheita e tratamento do cultivo - até as relações comerciais do sistema de produção agrícola. Neste contexto, partindo de um pressuposto histórico e socialmente construído pelo processo civilizatório colonial do patriarcado, o papel da mulher e a sua identidade foram predestinados aos afazeres domésticos e às habilidades manuais - sem um vínculo direto à atividade econômica - proporcionando, assim, uma relação desigual de papéis entre homens e mulheres, que ocasiona uma dependência social, financeira e até mesmo doméstica, entre ambos. Social e financeira nas famílias onde a mulher se torna refém do papel atribuído ao homem, não tendo seu trabalho quantificado e valorado; e doméstica onde o homem, sem o papel atribuído à mulher - que cuida dos(as) filhos(as) e da casa - não teria a possibilidade de produzir a força de trabalho que resulta na moeda de troca.

Este estudo tem como objetivo analisar o caso específico de uma organização de mulheres no âmbito rural que fazem parte de um movimento de contestação da ordem, na medida em que os papéis deixam de ser atribuídos por conveniência ou por dominação: Mulheres Organizadas Buscando Independência (MOBI), que trabaIham sobretudo na cafeicultura orgânica no município de Poço Fundo - MG. A partir disto, norteia-se pela abordagem fenomenológica acerca da percepção das integrantes sob diversos temas, como: a relação da mulher com o campo; a importância da produção orgânica; e a luta da mulher que busca independência; etc. Assim, deu-se voz às mulheres através de entrevistas, buscando compreender a importância desse grupo, em que as integrantes se encontram numa situação de igualdade e de solidariedade para com a luta das demais. Enfatiza-se, então, na análise dos frutos dessa união, a identificação seu significado para além da atividade econômica exercida.

Antemão, para compreender todas estas questões pontuais, faz-se necessária a análise dos temas individualmente tratados, como o conceito e a abordagem geográfica de gênero - acerca das discussões de gênero no campo, propriamente dito, no contexto da mulher no campo brasileiro - e a agroecologia, abordada no papel da mulher enquanto agente de transição e para a consolidação do sistema agroecológico.

\section{O GRUPO MULHERES ORGANIZADAS BUSCANDO INDEPENDÊNCIA - MOBI}

O grupo surgiu em 2006 a partir da união de quatro mulheres, cujas famílias já eram produtoras de café, cooperadas à Cooperativa dos Agricultores Familiares de Poço Fundo (COOPFAM), sendo a principal motivação da união a busca por direitos iguais nas decisões da cooperativa e a busca pela independência, como o próprio nome diz: Mulheres Organizadas Buscando Independência (MOBI). Em 2017 trinta mulheres compõem o grupo, sendo treze cooperadas produtoras de café orgânico, cinco cooperadas produtoras de café convencional e doze associadas que desenvolvem as demais atividades: cultivo de flores orgânicas, como rosas e copos de leite, e a confecção de artesanatos sustentáveis através do reaproveitamento de resíduos do café, como a palha e a borra. Além destas atividades, as mulheres também participam de vivências como cursos, seminários, palestras, entre outras.

Um dos frutos do grupo é o Café Orgânico Feminino, café cultivado sem a utilização de agrotóxicos, onde a produção é realizada do início ao fim pelas mulheres, sendo o diferencial da qualidade o seu sabor mais adocicado. A ideia da criação 
surgiu a partir do contato com uma compradora estadunidense que importava apenas cafés produzidos por mulheres. Assim, o primeiro container foi exportado para os Estados Unidos e hoje, além de comercializado no Brasil, é exportado para diversos países da Europa, para o Japão, Nova Zelândia e Austrália, onde a questão orgânica é vista sob outros aspectos em se tratando da valorização do sistema de produção. 0 grupo produz cerca de 1.700 sacas ao ano e mais da metade destas sacas são de Café Orgânico Feminino. Vale destacar que o café orgânico feminino tem um valor agregado de $20 \%$ sobre o convencional, por conta de todas essas questões que envolvem a produção, e principalmente, a valorização do trabalho da mulher.

A Cooperativa dos Agricultores Familiares de Poço Fundo e Região (COOPFAM) conta com mais de trezentas famílias de pequenos cafeicultores do município de Poço Fundo e da região do sul de Minas Gerais. A agricultura familiar em Poço Fundo, por grande influência da cooperativa, vem aos poucos sendo cada vez mais contemplada por aspectos agroecológicos, pela agricultura orgânica, solidária e inclusiva. Os exemplos dessa transformação podem ser vistos nos diversos projetos sociais e culturais desenvolvidos por ela, como além do MOBI, o projeto Arca de Letras que distribui pequenas bibliotecas pelas comunidades, incentivando a leitura e a alfabetização.

\section{A SIGNIFICAÇÃO DA REALIDADE CAPTADA A PARTIR DAS EXPERIÊNCIAS VIVENCIADAS}

Para o desenvolvimento desta pesquisa, partiu-se da fenomenologia para compreender as vivências e a participação das mulheres no MOBI e como esse grupo muda ou mudou o modo de ver e agir em sociedade. O ponto chave da fenomenologia como metodologia, segundo Holzer (1997, p. 78), é o fato "de reaproximar as ciências de nossas vidas, ações e projetos, a partir das experiências ante-predicativas (anteriores aos conceitos e aos juízos), ou seja, relativas à percepção do mundo e de seus objetos enquanto fundamentos dos conceitos". Assim, a ciência deve fazer sentido enquanto método de compreensão da realidade, portanto, se a realidade envolve vivências e sentimentos, a ciência deve dar conta de abarcá-la, quer seja pela mera descrição, afinal, sugerir algo pode ser mais construtivo do que concluir.

Também se deve considerar que, para Rocha (2003), a fenomenologia veio a fim de mostrar que o ser humano vê o mundo e seus fenômenos de acordo com sua cultura, meio ambiente, formação educacional, estado emocional, entre outros fatores que formam seu entorno e seu interior, compreendendo que cada indivíduo tem sua própria visão a partir de ideias já construídas ou que ela pode ser modificada pela introdução de novos conhecimentos.

A experiência tem uma conotação de passividade; a palavra sugere o que a pessoa tem suportado ou sofrido. Um homem ou mulher experiente é a quem tem acontecido muitas coisas [...] e os seres humanos são maduros ou imaturos dependendo de terem ou não tirado vantagens dos acontecimentos. Assim, a experiência implica a capacidade de aprender a partir da própria vivência. Experienciar é aprender; significa atuar sobre o dado e criar a partir dele. 0 dado não pode ser conhecido em sua essência. O que pode ser conhecido é uma realidade que é uns constructo da experiência, uma criação de sentimento e pensamento. (TUAN, 1983, p.18) 
Foram realizadas 10 entrevistas com um roteiro com quatro temas (história de vida, produção do café/artesanato, gênero e o grupo), na qual as mulheres pudessem contar suas experiências e seus comportamentos antes e depois da inserção no MOBI. A ideia das entrevistas abertas é deixar a entrevistada à vontade, de modo que seja compartilhado o máximo de detalhes e informações que possam subsidiar uma análise mais profunda. A entrevista foi realizada em agosto de 2017, na reunião mensal do MOBI que ocorre sempre na terceira sexta-feira de cada mês.

De acordo com Claval (1999) o que as pessoas recebem do mundo que as circunda e o que as pessoas experimentam, é devido a um espaço específico e à marca de cada época; o indivíduo não pode ter experiências pessoais, conhecer e se apropriar de novos ambientes, a não ser no local em que ele possui um cotidiano, e com isso, ele se "enraíza" e pode construir um sentimento de identidade. Ainda a respeito da identidade, Haesbaert (1999) argumenta que ela não é única, mas diversa, em que a definição de identidade se dá por intermédio de outras identidades e suas características demonstram-se nas condições espaço temporais em que um grupo se localiza. A identidade social criada através das relações identitárias, é estimulada e estimula um poder simbólico; para Bourdieu (1989, p.7-8) "o poder simbólico é, com efeito, esse poder invisível o qual só pode ser exercido com a cumplicidade daqueles que não querem saber que the estão sujeitos ou mesmo que o exercem".

Segundo Tuan (1983), no estudo do espaço no âmbito da geografia humanista, consideram-se os sentimentos espaciais e as ideias de um grupo sobre o espaço a partir da experiência; e os princípios fundamentais da organização espacial encontram-se na postura/estrutura do corpo humano e nas relações entre pessoas. Nossos corpos vivenciam o espaço de diferentes maneiras e este espaço é então lugar quando apreendemos nossa análise para a significação do mesmo, pela identificação e pertencimento. Ainda segundo Tuan (1983, p.14) "se pensarmos no espaço como algo que permite movimento, então lugar é pausa; cada pausa no movimento torna possível que localização se transforme em lugar". Nesse contexto, busca-se saber como o espaço de convivência do MOBI transformou as identidades das mulheres envolvidas, e quais suas repercussões deste fato em suas vivências cotidianas.

\section{CONCEITO E ABORDAGEM GEOGRÁFICA DE GÊNERO - A MULHER NO CAMPO}

A geografia, enquanto ciência que estuda as relações de produção, reprodução e apropriação do espaço, pode ser transcrita e observada na sociedade a partir de cinco víeis que traduzem a real história da civilização de forma justa e correlata, são eles: gênero, classe, raça, etnia e cultura. Para este trabalho, consideramos gênero o ponto chave enquanto categoria de análise, pois é a partir dele que a divisão de trabalho é explicitamente desenvolvida.

Saber o que é ou não tema passível de ser estudado pela Geografia depende da concepção de ciência que se estabelecem por aqueles que possuem o poder de ditar as regras do jogo científico. [...] se todas as experiências vividas pelas pessoas possuem uma dimensão espacial e as pessoas experienciam o mundo com seus corpos e seus corpos estão organizados socialmente pelo gênero, podemos afirmar 
que compreender as formas como homens e mulheres experienciam a vida e, por consequência, o espaço, é com toda certeza profundamente geográfico (SILVA, 2014, p.98).

Para Scott (1989, p.21) o gênero "é um elemento constitutivo de relações sociais, baseado nas diferenças percebidas entre os sexos, e o gênero é uma forma primeira de significar as relações de poder", assim, considera-se "gênero" a partir da diferenciação do trabalho e da contestação das atribuições de tarefas predominantes no campo; "gênero" não é sinônimo de mulheres e nem deve ser empregado no sentido de ter uma conotação mais objetiva e neutra; o seu uso enfatiza o sistema de relações existentes que pode incluir o sexo, mas que não é diretamente determinado por ele. Ainda para Scott (1995, p.71) "os que se propõem a codificar os sentidos das palavras lutam por uma causa perdida, porque as palavras, como as ideias e as coisas que elas significam tem uma história". Portanto, é uma luta perdida tentar travar um embate sobre a definição do que é próprio ao gênero masculino ou feminino por entre características físicas ou psicológicas a eles atribuídas e por entre as facetas da nossa linguagem e comunicação.

As normas de gênero são incorporadas pelas pessoas, regendo a inteligibilidade social das ações humanas; contudo, as normas são diferentes das ações, pois, ao experienciar as normas de gênero, as pessoas não apenas as reproduzem como as transformam, escapando do padrão idealizado de masculinidade e/ou feminilidade. Por exemplo, há pessoas com uma anatomia classificada como feminina. 0 corpo dessa pessoa recebe toda a carga cultural e social de seu gênero, contudo, ao viver a vida ela pode incorporar elementos que não são exatamente considerados próprios de seu gênero. Uma menina que desenvolve habilidades esportivas, força e agressividade (elementos tradicionalmente ligados ao universo masculino) está também desconstruindo a ideia de gênero feminino em sua vida cotidiana. (BUTLER, 2004 apud SILVA, 2014, p 106-107)

Nas relações de produção do espaço, a questão de gênero é tratada como secundária, mas é de extrema importância para entendermos os conflitos e as contradições que residem no campo brasileiro. Para Silva (2014, p.112) "quando se toma o masculino como referente universal e se retira o feminino das relações, há uma clara expressão da invisibilidade [...] é justamente na naturalização da invisibilidade feminina e da centralidade masculina que se constrói de forma sutil a hierarquização entre os gêneros".

Portanto, "gênero no campo" perpassa pelas relações de dominação e poder existentes no mundo rural, cujo ambiente tem sido palco de um crescente engajamento político das mulheres nas últimas décadas. De acordo com Heredia (2006, p.06) "as primeiras organizações específicas de mulheres rurais datam do início dos anos 80, estimuladas principalmente pela igreja católica, movimento sindical e partidos políti$\cos ^{\prime \prime}$. No decorrer dos anos, muitas vezes as organizações passam a surgir pelas próprias mulheres, quando tomadas em si por assunção, ao mobilizar-se na busca por seus direitos. Segundo Siliprandi (2015, p.37) "o feminismo é uma teoria militante, porque, denunciando vieses ilegítimos que obscurecem o conhecimento, pode ser também um instrumento para a mobilização social, abrindo espaço para que os grupos oprimidos (no caso, as mulheres) se organizem em prol de mudanças sociais" partindo do pressuposto conjuntural das relações hierárquicas de gênero. 


\section{AGROECOLOGIA: A MULHER COMO AGENTE DA TRANSIÇÃo E DA CONSOLIDAÇÃO DO SISTEMA}

Segundo Altieri (2004, p.23) a agroecologia "utiliza os agroecossistemas como uma unidade de estudo, ultrapassando a visão unidimensional - genética, agronomia, edafologia - incluindo dimensões ecológicas, sociais e culturais", assim, ela fornece uma compreensão mais profunda da natureza e dos princípios que a regem, integrando princípios agronômicos, ecológicos e socioeconômicos que proporcionam um entendimento sobre os sistemas agrícolas e a sociedade como um todo; e uma abordagem agroecológica incentiva os pesquisadores a adentrar nos conhecimentos tradicionais e nas técnicas dos agricultores para desenvolver plantios com uma dependência mínima de insumos agroquímicos ou externos.

A prática e a transição agroecológica visa preservar a diversidade e a especificidade de cada agente que é, ao mesmo tempo, produto e produtor do espaço, pois, segundo Rossini (1993, p.05) "a concentração fundiária, que elimina parte considerável das pequenas unidades familiares, provoca também a diminuição do uso da mão de obra, em especial da feminina, ao mesmo tempo em que a agricultura de subsistência tende a se tornar, cada vez mais, uma 'instituição' em extinção". A Articulação Nacional de Agroecologia (ANA) - fundada em 2002, afirma que "a igualdade das relações entre homens e mulheres é condição essencial para o alcance da sustentabilidade da produção agroecológica familiar.

A agroecologia é um movimento relativamente novo no Brasil, e há estudos que mostram que, muitas vezes, são as mulheres que iniciam a "conversão" da propriedade para sistemas sustentáveis, por estarem mais envolvidas com as propostas que tratam da saúde e da alimentação das famílias. Porém, em função da forma como se organizam as relações de produção e as relações familiares nesse tipo de agricultura, é comum que, quando o empreendimento começa a ter resultados positivos, o comando das atividades volte para as mãos dos homens. (SILIPRANDI, 2015, p.27)

As mulheres, para Siliprandi (2015, p.18) "se nutrem de esperanças - não a esperança dos que esperam, mas a do verbo esperançar, como nos ensina o educador Paulo Freire, com o sentido de se levantar, construir e não desistir! Esperançar como ato de juntar-se e agregar-se em renovadas formas organizativas, refazendo 0 presente e projetando um futuro novo" assim, elas reinventam a história e revolucionam conceitos e práticas.

\section{OS RELATOS DAS MULHERES DO MOBI}

Quem teve a ideia para começar a produzir orgânico e como foi a transição? Entrevistada 5: "Eu que tive a ideia de produzir orgânico. A gente tinha um vizinho fazendeiro e ele foi lá em casa um dia e comentou do assunto e eu fiquei apaixonada! Eu já tinha essa preocupação com a natureza... Pra mim era um sonho que hoje tá realizado! Por exemplo, meus filhos trabalham no meio da lavoura, sem nenhum medo de contaminação. A minha netinha, quando vem no final de semana, brinca no monte de café, vai no meio da lavoura e eu não tenho preocupação com nada."

Qual a maior dificuldade para a transição orgânica? Entrevistada 5: "O manejo que é um pouco difícil, porque com muita praga é difícil e só na enxada tem que ter 
mais mão de obra, fica mais caro. Na questão de produtividade era um problema no início, mas hoje a gente já conseguiu superar essa etapa, com o auxílio técnico da cooperativa. As lavouras orgânicas às vezes dá até mais que as convencionais."

Qual a importância de se produzir orgânico? Entrevistada 1: "É uma segurança pra minha família. Eu não tô sujeita a trabalhar com veneno e sou uma pessoa independente porque produzo toda a alimentação dentro da minha propriedade. Eu tenho a responsabilidade e tranquilidade de tá vendendo um produto de qualidade, que vai oferecer pra minha família e pra quem consome, saúde!" Entrevistada 3: "A gente não planta café orgânico pela questão do preço, é questão de um estilo de vida né, que é trabalhar com as coisas naturais, que seja benéfica e traga saúde e qualidade de vida... Acho que essa é a maior importância."

Como funcionam as decisões entre você e seu esposo na sua casa? Entrevistada 2: "Em casa é muito equilibrado, a gente se entende bem mas a gente vê que em muitas propriedades a mulher não aparece, nem na certificação do próprio café... a mulher só aparece quando serve o café, como se não fizesse nada." Entrevistada 4: "A gente interage muito, se vai resolver sobre a venda do café, vê o preço e nunca vende sem a opinião do outro."

Por que as mulheres são diferentes dos homens? Entrevistada 1: "Eu não acho que somos diferentes dos homens! Depende do comando da mulher, se ela se sentir diferente, ela é! Tem homens muito cuidadosos, assim como tem mulher que não é cuidadosa, mas vejo que Deus nos fez tão sagradas e perfeitas que nós somos as únicas que podemos dar a vida! Me sinto muito grata e vejo que nós somos muito poderosas e empoderadas por isso. Eu não vejo que a mulher ou o homem vem pra dividir força, acredito que vem pra somar por ambas as partes." Entrevistada 3: "Mulher é mais sensível, mais delicada em tudo! Não adianta..." Entrevistada 4: "A maior dificuldade é em termos de negociar, se o marido for vender, ele é mais valorizado do que a mulher vendendo." Entrevistada 5: "Acho que as mulheres são mais detalhistas, são mais pacientes. A gente brinca que, com o café mesmo, a gente tem um carinho mais especial, porque o homem às vezes joga de qualquer jeito lá no terreiro."

Qual a maior dificuldade para a mulher que trabalha no campo? Entrevistada 1: "Não vejo dificuldade nem diferença no trabalho da mulher no campo! A dificuldade para a mulher é o freio de ideias, só isso! Se você acreditar que você não pode, não é só não poder na agricultura não... você não pode ser médica, não pode fazer nada, porque você é mulher... Eu acho que a gente tem que sentir que é dona do espaço e ter o protagonismo no local." Entrevistada 2: "A mulher é muito submissa porque não reconhece o valor que tem. A gente tem esse papel de mostrar nosso valor..." Entrevistada 5: "Lá no grupo você vê mulheres que faz tudo sozinha, tudo! Ta no regimento do grupo que o gerenciamento e a responsabilidade de todo o processo de produção é pela mulher, mas isso não quer dizer que ela tenha que pegar a enxada e ir pra roça, pode contratar homem pra ajudar e pagar por esse serviço."

Como as mulheres podem se tornar independentes? Entrevistada 1: "A independência deve partir das próprias mulheres. As mães não devem tratar os filhos com diferenças. Usar um dinheiro ou um carro junto com o esposo, não é ser submissa, é ser parceira." Entrevistada 3: "Em casa o dinheiro é nosso, ele trabalha mas eu também faço as coisas em casa, então é nosso igual." Entrevistada 4: "Falta muito pra mulher se tornar independente porque a sociedade tem muito machismo. A gente tem que ir à luta..." Entrevistada 5: "Pra independência o econômico faz muita diferença, principalmente na minha realidade, o homem passa a respeitar a mulher quando ele começa a ver resultados financeiros. A partir do momento que ela conseguir essa independência financeira, consegue todas as outras. 
Qual o significado do MOBI para você? Entrevistada 1: "Auto-estima e confiança. Aqui é um grupo. Pode chamar de um grupo feminista, um grupo de resistência, o que for... É um grupo, que pensa igual, que decide igual, que fala o que quer. Tem que acreditar!" Entrevistada 3: "Ele te envolve com seus problemas e cada uma tenta ajudar como pode. A amizade aqui é muito grande né, a gente tem um grupinho lá no whatsapp e tudo o que tem a gente coloca lá. "Todo mundo ali sente liberdade para ajudar e se por no lugar da outra." Entrevistada 4: "O grupo significa ajudar a liderar mais na sociedade né, aqui vamos tendo exemplos e aprendendo."

O que mudou na vida após começar a participar do grupo? Entrevistada 1: "Adquiri conhecimento, contato com alunos, professores. Eu costumo dizer que a faculdade que eu não tive, eu fiz aqui." Entrevistada 2: "Mudou minha autoestima, a melhora na timidez, na qualidade de vida. Hoje sou outra pessoa!" Entrevistada 5: "Mudou tudo, porque era tudo o que eu queria, sabe? Eu me apaixonei!"

Sobre a experiência de participar do grupo, o que mais te marcou? Entrevistada 1: "O que mais me marca é o ser humano. O ser humano, quando ele é humano, não é porque ele é o melhor professor que ele se sente melhor diante de alguém, quando ele é humano ele é bom no que faz porque ele tem mérito pelo que faz." Entrevistada 2: "A maior experiência é quando a pessoa tá passando por um momento difícil e o grupo inteiro vai visitar e dar apoio, a gente sente amizade, sente aquela força humana..." Entrevistada 3: "Os encontros são ótimos! Semana que vem mesmo vamos reunir numa casa pra fazer sabão e é um barato, cê precisa de ver! É muito gostoso, faz bem! Todo mundo aqui no grupo se sente acolhido."

Defina o MOBI em três palavras. Entrevistada 1: "União, força e fé." Entrevistada 2: "Uma grande família." Entrevistada 3: "União, amizade e persistência." Entrevistada 4: "Amizade, família e amor." Entrevistada 5: "União, amizade e força."

Por que a luta da mulher e do MOBI é importante? Entrevistada 1: "A gente vê que tem um grupo grande de mulheres que são machistas e a luta é importante porque uma varinha sozinha é fácil de quebrar, mas várias fortalece!" Entrevistada 2: "A luta do MOBI é importante porque a gente se sente reconhecida e valorizada, incentivada pra fazer muito mais!" Entrevistada 3: "Tem muitas mulheres aqui que desde criança trabalham na roça, então é uma maneira de valorizar o trabalho delas, pra dar exemplo pra jovem que está vindo aí, que não tenha vergonha de se tornar uma produtora rural, pra ela não ir embora para a cidade por conta de falta de reconhecimento no campo. E cê viu ali né?! A mulherzada tudo chique e bonitona, não tem ninguém desarrumada ali não, trabalha na roça mas é vaidosa também!" Entrevistada 4: "É importante pra mudar o país! As mulheres se preocupam mais com a saúde e conseguem abranger a família toda a ir pelo lado do orgânico." Entrevistada 5: "Sem a luta nunca vai existir igualdade. A mulher trabalha na roça com o marido de sol a sol e na hora que vai comprar uma blusa, tem que pedir dinheiro pro marido como se pedisse um favor, sendo que é um dinheiro delas, por direito! Existe ainda um machismo mesmo nas entrelinhas, mesmo disfarçado, você ainda sente... Sente num comentário, sente no próprio bairro, com os próprios familiares, que mulher é pra ficar em casa no tanque e no fogão, existe essa mentalidade muito forte na zona rural. Mas eu não preocupo muito com isso não, porque isso sempre vai existir. Já melhorou muito nessa questão de discriminação e preconceito Eu dirijo, saio, viajo e vejo que o machismo está às vezes mais nas outras mulheres do que nos homens. As vizinhas, as parentes, são as que mais implicam. É triste ver a própria mulher assim. Tem que ir quebrando isso e eu acho que a melhor forma de quebrar isso é na educação." 


\section{CONSIDERAÇÕES FINAIS}

Na análise dos relatos das participantes, é nítida a importância do grupo em suas vidas, pois este estimula o crescimento individual a partir do coletivo, e viceversa, enquanto mulheres que se organizaram e visualizaram a independência, através da auto-percepção enquanto pessoas autônomas, como um aspecto tangível e alcançável. A auto-estima é continuamente fomentada e o convívio com as demais mulheres é gratificante pela criação de um vínculo afetivo e de confiança. O grupo, então, adquire um significado de lugar, dada na pausa do espaço das atividades e no pertencimento das participantes para com ele, pois quer onde ele esteja reunido, as participantes se sentem "em casa".

O processo de empoderamento político e feminino se manifesta, quando esta autonomia transpassa o ambiente do grupo, atuando como vozes ativas em seus trabalhos, suas famílias, bairros ou espaços de convívios coletivos, onde as mulheres, quando auto-reconhecidas, se fazem reconhecer. Entretanto, como que num poder simbólico, estas mulheres do MOBI levantam a bandeira de um grupo que busca independência, sem a nomeação ou a auto-percepção de um feminismo, mas de uma "luta". O poder, quando invisível, por vezes se manifesta de forma mais construtiva, porque o seu resultado posterior ao longo de um processo de desenvolvimento é espontâneo, e não previamente intitulado. O feminismo é um conceito, por vezes acadêmico ou de um grupo seleto, mas que ainda não abrange todas as mulheres, e que talvez nunca abranja a vastidão de práticas, atitudes e participações femininas na sociedade, não intituladas "feministas".

É importante refletir sobre como as relações funcionam e como elas podem mudar... Além da questão do gênero no campo e da sucessão da estrutura familiar da agricultura, a problemática perpassa pela produção agrícola que, num contexto geral, inserida no sistema capitalista, estimula a competitividade da produção, em especial quando consideramos a marginalização dos agricultores familiares produtores de café no sul de Minas: a matéria-prima em si é barateada e a valorização é decorrente do processo de transformação industrial ou ainda quando a produção dos grandes proprietários obtém êxito econômico facilmente, através da utilização de insumos externos e agrotóxicos para potencializar a produção.

Assim, a pesquisa proporcionou uma análise pontual das mulheres do MOBI, lutadoras e resistentes no campo. A lógica de sucessão na família rural é o abandono da mulher no campo ou a submissão de sua função quanto à gestão da propriedade realizada pelo pai ou marido - neste caso, as mulheres tomam a frente da produção. A equidade de gênero para a ascensão da agroecologia desafia o capitalismo e, consequentemente, o agronegócio que além de dificultar a manutenção e continuação das famílias no campo, muito menos possibilita um maior engajamento nas atividades ligadas à agricultura, em função da mecanização e da desvalorização do trabalho manual, em especial das mulheres.

\section{REFERÊNCIAS}

ALTIERI, Miguel. Agroecologia: a dinâmica produtiva da agricultura sustentável. Traduzido por Marília Marques Lopes. 4.ed. Porto Alegre: Editora da UFRGS, 2004.

BOURDIEU, Pierre. O poder simbólico. Lisboa: DIFEL, Rio de Janeiro: Bertrand Brasil, 1989. 
CLAVAL, Paul. A Geografia Cultural: O Estado da Arte. In: ROSENDAHL, Z; CORRÊA, R.L. (Org.) Manifestações da cultura no espaço. Rio de Janeiro: Ed. Uerj, 1999. p. 59-98.

HAESBAERT, Rogério. Identidades territoriais. In: CORRÊA, Roberto Lobato; ROSENDAHL, Zeni. (Org.). Manifestações da cultura no espaço. Rio de Janeiro: Editora da UERJ, 1999, p. 169-189.

HEREDIA, Beatriz Maria Alasia. Gênero e acesso a políticas públicas no meio rural brasileiro. Revista NERA. Presidente Prudente, SP - ano 9, n. 8, p. 1-28, jan./jun. 2006.

HOLZER, Werther. Uma discussão fenomenológica sobre os conceitos de paisagem e lugar, território e meio ambiente. p.77-85. Revista Território. ano II, n.3, 1997

ROSSINI, Rosa Ester. Geografia e gênero: A mulher como força de trabalho no campo. Informações Econômicas, SP - vol. 23 (Supl.1),1993.

SCOTT, Joan. Gênero - uma categoria útil de análise histórica. Educação e Realidade, Porto Alegre, RS - vol. 1, n. 2, jul./dez. 1995. p.71-99.

ROCHA, Lurdes Bertol. Fenomenologia, semiótica e geografia da percepção: alternativas para analisar o espaço geográfico. Revista da Casa da Geografia de Sobral.v.4/ 5, p.67-79, 2002/2003.

SILIPRANDI, Emma. Mulheres e agroecologia: transformando o campo, as florestas e as pessoas. Rio de Janeiro: Editora UFRJ, 2015.

SILVA, Joseli Maria. Gênero e espaço: esse é um tema para a Geografia? In: AZEVEDO, Daniel A.; MORAES, Marcelo Alonso. (Org.). Ensino de Geografia: novos temas para a geografia escolar. 1ed. Rio de Janeiro: Consequência, 2014.

TUAN, Yi-Fu. Espaço e lugar: a perspectiva da experiência. São Paulo: Difel, 1983. 